\title{
Value-based provider payment: towards a theoretically preferred design
}

\author{
Daniëlle Cattel $^{\star}$, Frank Eijkenaar and Frederik T. Schut \\ Erasmus School of Health Policy and Management, Erasmus University Rotterdam, Rotterdam, The Netherlands \\ ${ }^{*}$ Correspondence to: Erasmus School of Health Policy and Management, Erasmus University Rotterdam, Box 1738, 3000 \\ DR Rotterdam, The Netherlands. Email: cattel@eshpm.eur.nl
}

(Received 1 June 2017; revised 16 April 2018; accepted 30 July 2018; first published online 27 September 2018)

\begin{abstract}
Worldwide, policymakers and purchasers are exploring innovative provider payment strategies promoting value in health care, known as value-based payments (VBP). What is meant by 'value', however, is often unclear and the relationship between value and the payment design is not explicated. This paper aims at: (1) identifying value dimensions that are ideally stimulated by VBP and (2) constructing a framework of a theoretically preferred VBP design. Based on a synthesis of both theoretical and empirical studies on payment incentives, we conclude that VBP should consist of two components: a relatively large base payment that implicitly stimulates value and a relatively small payment that explicitly rewards measurable aspects of value (pay-for-performance). Being the largest component, the base payment design is essential, but often neglected when it comes to VBP reform. We explain that this base payment ideally (1) is paid to a multidisciplinary provider group (2) for a cohesive set of care activities for a predefined population, (3) is fixed, (4) is adjusted for the population's risk profile and (5) includes riskmitigating measures. Finally, some important trade-offs in the practical operationalisation of VBP are discussed.
\end{abstract}

Keywords: value-based payments; global payments; pay-for-performance; accountable care

\section{Introduction}

Worldwide, there is dissatisfaction with current, input-oriented and supply-led health care systems. These systems are characterised by monodisciplinary and segmented care and result in fragmented care processes, suboptimal quality and waste of resources (Porter \& Teisberg, 2006; Berwick, 2011; De Bakker et al., 2012; Mechanic \& Tompkins, 2012; Pronovost, 2013; Tsiachristas, 2015). There is consensus that flawed provider payment methods contribute to this problem (McGuire, 2000; Porter \& Teisberg, 2006; McGuire, 2011). In particular, predominant payment methods generate perverse incentives for health care providers regarding the delivery of services. For example, fee-for-service (FFS) - in which providers are paid retrospectively for each service delivered - is still a very common payment method in health care (especially in the United States) because it is relatively easy to administer and encourages productivity (Jegers et al., 2002; Marmor et al., 2011). However, this payment method may generate a 'more-is-better culture' and therefore tends to overprovision. In addition, providers who promote population health and successfully prevent treatment are financially penalised for that (Jegers et al., 2002; Ellis \& Miller, 2008). Another widespread payment method (especially in Europe) is capitation, in which providers receive a fixed amount per person per period. This payment method also has

(C) Cambridge University Press 2018. This is an Open Access article, distributed under the terms of the Creative Commons Attribution licence (http://creativecommons.org/licenses/by/4.0/), which permits unrestricted re-use, distribution, and reproduction in any medium, provided the original work is properly cited. 
important drawbacks, such as encouraging underprovision and risk selection (Porter \& Kaplan, 2016). Furthermore, both FFS and capitation (as well as other predominant payment methods) do not reward the provision of high-quality care and innovation. Finally, because these methods traditionally remunerate single, monodisciplinary providers instead of multidisciplinary groups of providers, they preserve fragmentation and thwart cooperation and coordination across the continuum of care (Epping-Jordan et al., 2004; Van Exel et al., 2005). In short, predominant payment methods are not fully aligned with 'value'.

In order to tackle the problems related to current payment methods, worldwide, policymakers and purchasers of care are exploring alternative payment strategies to help steering health care systems towards value (Conrad et al., 2014; Burwell, 2015). A well-known endeavour in this regard is pay-for-performance $(\mathrm{P} 4 \mathrm{P})$, in which providers are explicitly rewarded for 'doing a better job'. Although $\mathrm{P} 4 \mathrm{P}$ is an appealing idea, explicit financial incentives for value should in principle be used only modestly in provider payment methods because of the multitasking problem (Holmstrom \& Milgrom, 1991; see section 3.2).

Therefore, it is not surprising that in practice, the majority of provider revenues (typically referred to as the base payment) is not explicitly linked to value. This base payment, however, does create implicit (dis)incentives for value, because each payment method influences providers' behaviour through incentives (Jensen \& Meckling, 1976; Enthoven, 1988; Prendergast, 1999; McGuire, 2000; Gaynor et al., 2004; Berenson, 2010; Christianson \& Conrad, 2011; McGuire, 2011). In this paper, we underline the importance of carefully considering the design of particularly these implicit financial incentives, in such a manner that desired behaviour is fostered and value is incentivised. We discuss a theoretically preferred design of a payment method that both implicitly and explicitly stimulates value in a broad sense, henceforth referred to as value-based payment (VBP).

There is substantial literature on the theory and implementation of payment incentives (for an overview, see McGuire, 2000; McGuire, 2011; Conrad et al., 2014; Conrad, 2015; Conrad et al., 2016). However, the theoretical basis of VBP design is fragmented and in the available work, the terms 'value' and 'VBP' are often implicitly used for different dimensions of value. In addition, the relationship between what a health care system ideally pursues in terms of value and what is required in terms of the VBP design to achieve this has not been explicated. Therefore, this paper aims at: (1) identifying key-value dimensions that are ideally stimulated by VBP and (2) constructing a conceptual framework of a theoretically preferred VBP design according to these dimensions. We achieve these goals based on a synthesis of findings of key theoretical and empirical studies conducted in the field of health services research, health economics, contract theory and the general economic theory on incentive design. Throughout, we relate our findings to VBP initiatives from practice, and end with illustrating some important trade-offs in the practical operationalisation of VBP. The insights from this paper are of practical relevance for policymakers and purchasers who are responsible for (re)designing existing and future VBP initiatives.

The structure of this paper is as follows. In the next section, key-value dimensions are discussed, followed by a section containing a concise theoretical background on payment methods. The fourth section focusses on a theoretically preferred VBP design. Section 5 illustrates several important trade-offs in the practical operationalisation of VBP, followed by some concluding remarks.

\section{Key-value dimensions in health care}

In previous work, the term 'value' in health care has been defined in different ways. According to the Institute of Medicine (IOM, 2001), health care needs to be safe, effective, patient-centred, timely, efficient and equitable. Berwick et al. (2008) state that a health care system should pursue a Triple Aim of limiting per capita cost of care, improving individual patient experience and improving population health. Porter $(2009,2010)$ provides a more global description of health care system goals, namely maximal value, defined as the best health outcomes achieved per dollar 
spent. Value encompasses efficiency and the central focus is on multidimensional outcomes, rather than inputs and processes. Conrad (2015) defines value as maximum health benefit (i.e. health outcomes, processes of care and patient experience) at minimum cost.

Based on these descriptions as well as arguments derived from the societal debate on what stakeholders in health care should ideally aim for (Eijkenaar \& Schut, 2015), five key-value dimensions can be distinguished:

1. High-quality care. Care is safe, effective, patient-centred and timely. High quality comprises 'technical' or clinical quality as well as patient-reported measures regarding individual care paths and outcomes (e.g. PROMs). Technical quality can be operationalised in structures (e.g. having an up-to-date patient registry for diabetes patients affiliated with the primary care practice), processes (e.g. regularly checking the blood glucose levels of diabetes patients) and (intermediate) outcomes (e.g. acceptable blood sugar levels for diabetes patients or absence of diabetes-related complications) (Donabedian, 1988).

2. Cost-conscious behaviour. Scarce resources are efficiently used, so there is no misuse or overuse.

3. Well-coordinated care. Multidisciplinary providers communicate and cooperate well in order to realise integrated, well-orchestrated care across the continuum of care. This dimension mainly regards coordination between providers of different disciplines and sites. A team-based approach in which multidisciplinary providers work side-by-side is of great importance, particularly given the increase in the number of individuals with multiple (chronic) diseases.

4. Cost-effective innovation. Cost-saving services result in equal or better health and healthpromoting innovations are worth the additional costs.

5. Cost-effective prevention. Deteriorations of health problems are prevented in a costeffective way. This dimension entails primary, secondary and tertiary prevention.

In this paper, a payment method is considered 'value-based' if it simultaneously provides incentives for all dimensions. Clearly, these dimensions are interrelated. For instance, wellcoordinated care can be considered an element of high-quality care. However, for the purpose of describing a theoretically preferred VBP design, it is necessary to explicitly distinguish the different dimensions of value. Note, however, that it is not the goal of this paper to develop indicators for measuring value. As we will argue below (Section 3.2), the measurement of all aspects of value and calculating payments only based on indicator scores is neither feasible nor desirable.

\section{Theoretical background on provider payment methods}

\subsection{Financial incentives to counterbalance agency problems}

Agency theory, as part of contract theory, studies the relation between two contracting parties: the principal and the agent (Spence \& Zeckhauser, 1971; Ross, 1973). In this paper, the focus is on the health care provider acting as a double agent, interacting with both the patient and the purchaser (Blomqvist, 1991). Information asymmetry between providers as the relatively wellinformed party relative to patients and purchasers is not a problem, as long as the interests of all involved parties are aligned (Laffont \& Martimort, 2002). However, in case of conflicting interests, agency problems may evolve and providers may exploit their information surplus for their own (financial) benefit (Jensen \& Meckling, 1976; Richardson, 1981).

An important strategy to counterbalance agency problems entails 'controlling' the agent by means of (financial) incentives (Vermaas, 2006). The goal of controlling is to align providers' interests with those of patients' and 'purchasers' and is based on the assumption that providers are in the position to improve value if they are motivated to do so. Providers' responsiveness to 
financial incentives has been well documented in the literature, implying that the (design of the) payment method is an important factor influencing providers' behaviour and can thus be used to help steering health care systems towards value (Jensen \& Meckling, 1976; Enthoven, 1988; Prendergast, 1999; McGuire, 2000; Gaynor et al., 2004; Berenson, 2010; McGuire, 2011).

\subsection{The need for a base payment}

Ideally, providers who are 'doing a good job' in terms of key-value dimensions are explicitly rewarded for this. A prerequisite of a payment method based fully on providers' performance with respect to value is that all aspects of value can be captured in the payment contract (i.e. for each aspect an indicator is available on which providers can be 'scored'). Complete contracts are, however, unfeasible in health care since the outcomes of some of the multiple tasks that providers perform, are more difficult (or even impossible) to measure objectively than others. For instance, for some medical interventions reliable and valid outcome indicators are available, whereas for other care activities - e.g. good communication and coordination of care - the added value is difficult to measure and appropriate registries are lacking. This problem has been referred to as the multitasking problem (Holmstrom and Milgrom, 1991; Eggleston, 2005; Frølich et al., 2007) and is defined as the challenge of designing incentives to motivate appropriate effort across multiple tasks when the desired outcomes for some tasks are more difficult to measure than others (Eggleston, 2005). An important potential consequence of this challenge is that explicitly rewarding providers for some specific aspects of value may result in undesired behaviour. Specifically, providers may focus disproportionately on those tasks that are measured and rewarded and neglect unincentivised tasks. This phenomenon has been referred to as 'teaching to the test' (Holmstrom \& Milgrom, 1991) and has actually been observed in practice (Steel et al., 2007; Glickman et al., 2007; Campbell et al., 2009; Mullen et al., 2010).

Due to the multitasking problem and the associated risk of teaching to the test, explicit financial incentives for value can and should be used only modestly in provider payment methods. As a consequence, the majority of providers' revenues can and should not be explicitly related to value. This part of providers' revenue is commonly referred to as the base payment. This base payment will typically comprise the largest part of total provider payment, whereas the payment component explicitly related to performance indicators (P4P) is likely to be relatively small. Indeed in practice, base payments currently comprise at least $90 \%$ of total provider payment (Eijkenaar, 2013; Ryan et al., 2015; Milstein \& Schreyögg, 2016). So far, papers investigating VBP reform have focussed mainly on the design of the relatively small P4P component. Being the largest payment component, however, the design of the base payment is at least equally and arguably more important.

\subsection{Shortcomings of predominant and alternative base payment methods}

The four most frequently applied base payment methods in practice are payment per item-ofservice (FFS), payment per case (e.g. DRG’s), payment per person (capitation) and payment per period (salary for individual providers and fixed budget for organisations). In Table 1, the incentives generated by these methods in relation to the key-value dimensions are summarised, based on Jegers et al. (2002), Ellis \& Miller (2008) and Christianson \& Conrad (2011). This table shows that, although each payment method to some extent stimulates at least one key-value dimension, other dimensions are not incentivised or even discouraged.

As none of the predominant base payment methods adequately promotes all key-value dimensions, alternative base payment methods have been developed. One example is combining predominant methods with opposing incentives in order to sustain the favourable elements of each method, while neutralising the drawbacks (Ellis \& McGuire, 1986; Robinson, 2001; Christianson \& Conrad, 2011; McGuire, 2011). Unfortunately, it is still unlikely that all value dimensions are stimulated under these mixtures (see Table 1, for a mixed payment method of 
Table 1. Base payment methods and their incentives for key-value dimensions ${ }^{a}$

\begin{tabular}{|c|c|c|c|c|c|}
\hline & $\begin{array}{l}\text { High- } \\
\text { quality } \\
\text { care }\end{array}$ & $\begin{array}{l}\text { Cost- } \\
\text { conscious } \\
\text { behaviour }\end{array}$ & $\begin{array}{l}\text { Well- } \\
\text { coordinated } \\
\text { care }^{b}\end{array}$ & $\begin{array}{c}\text { Cost- } \\
\text { effective } \\
\text { innovation }\end{array}$ & $\begin{array}{l}\text { Cost- } \\
\text { effective } \\
\text { prevention }\end{array}$ \\
\hline Payment per item-of-service & \pm & - & - & - & - \\
\hline Payment per case & \pm & \pm & - & \pm & - \\
\hline Payment per person & - & + & - & - & + \\
\hline Payment per period & - & \pm & - & - & \pm \\
\hline $\begin{array}{l}\text { Mixed payment method of } 50 \% \\
\text { FFS and } 50 \% \text { capitation }\end{array}$ & \pm & + & $-b$ & - & \pm \\
\hline $\begin{array}{l}\text { Bundled or episode-based } \\
\text { payment }\end{array}$ & \pm & \pm & \pm & \pm & - \\
\hline
\end{tabular}

FFS $=$ fee-for-service.

'Authors' own analysis.

${ }^{b}$ By definition, no incentives for well-coordinated care exist because in these examples the payment is assumed to apply to a single, monodisciplinary provider.

$50 \%$ FFS and $50 \%$ capitation). Another recent example of an alternative base payment method is bundled or episode-based payment (De Brantes et al., 2009; Mechanic \& Altman, 2009; De Bakker et al., 2012; Ridgely et al., 2014). Although bundling stimulates cost-conscious behaviour and well-coordinated care, value is only stimulated to some extent and only for those services inside the bundle (Wilensky, 2014; Table 1).

\section{A theoretically preferred VBP design}

\subsection{Core components of a theoretically preferred VBP}

Building on the theory as discussed in Section 3, a theoretically preferred VBP should consist of two core components: (1) a substantial base payment that implicitly stimulates key-value dimensions and (2) a relatively small variable payment that explicitly rewards some measurable aspects of value dimensions ( $\mathrm{P} 4 \mathrm{P})$. A base payment is a vital component of a theoretically preferred VBP because of the multitasking problem and the risk of teaching to the test when using high-powered explicit incentives (Section 3.2). Nevertheless, relatively small explicit rewards are a crucial component of a theoretically preferred VBP. This payment component is required to ensure that value aspects that are not or cannot be implicitly incentivised by the base payment, are given sufficient attention by providers. The variable payment is particularly suitable for stimulating aspects of value that can be relatively easily and objectively measured and that are difficult to incentivise implicitly (Vlaanderen et al., 2018). Typically, these aspects are related to the value dimension 'high-quality care' since a broad spectrum of indicators has already been developed and is increasingly becoming available as a result of an increasing number of P4Pexperiments and initiatives employed by the International Consortium for Health Outcomes Measurement (ICHOM). Other measurable aspects of other value dimensions, however, can be part of the variable payment as well (e.g. smoking cessation counselling as an element of costeffective prevention; Lindenauer et al., 2007; Mendelson et al., 2017).

The two components should be well tailored to ensure every value dimensions is implicitly and/or explicitly incentivised by VBP. The variable payment can be either designed as an 'addon' to the base payment or as an integral part. The first modality is similar to most current P4Pprograms, while in the latter modality receiving (part of) the base payment is conditional on meeting specific value targets. Note that the relative shares of the two components may vary over time and may depend heavily on the specific context (see Section 5). For instance, if better 
performance indicators become available, the share of the variable component that explicitly rewards high quality may increase relative to the base component.

In practice, there are several payment methods that come close to the theoretically preferred VBP design as described above. Box 1 provides a description of three prominent examples. In the remainder of this paper, we relate our findings to these examples.

Box 1. VBP practice initiatives.

\begin{abstract}
Medicare accountable care organisations (ACOs)
ACOs are networks of health care providers that are jointly accountable for a share of the financial and clinical outcomes of a defined population during a predetermined period. Examples of public sector ACO models are the Medicare Pioneer ACO model and the Medicare Shared Savings Program (MSSP). Under the MSSP, a global budget based on the historical expenses of an assigned population of Medicare FFS beneficiaries is calculated. This 'benchmark' is corrected for national growth and is adjusted for population risk. Shared savings (and losses) are determined by comparing the benchmark to the ACO's actual expenditures and are conditional on meeting a minimum savings rate and quality standard. Assignment of the population to ACOs is mainly done retrospectively (Pham et al., 2010; Lewis et al., 2013; Song, 2014; McWilliams et al., 2015; Rose et al., 2016).

The alternative quality contract (AQC)

The AQC is a 5-year ACO agreement in the private sector introduced by Blue Cross Blue Shield of Massachusetts (BCBS). Under the AQC, an annual fixed payment is provided, based on a per member per month amount. Providers are responsible for the total continuum of care for a defined population of enrolees, that is prospectively attributed to a provider group by means of the affiliation of their designated primary care physician. The base payment is set using historical expenses and is adjusted periodically for (changes in) health risk. The base payment and future increases thereof (i.e. annual growth rates) are negotiated between provider groups and BCBS. Providers share both financial savings and losses. In addition to the global budget, providers who meet quality benchmarks are explicitly rewarded via the P4P-program (a bonus of maximal 10\% of the global budget). Shared savings and losses directly depend on the quality score as well; as quality improves (declines), the share of providers' deficit decreases (increases) while the share of providers' surplus increases (decreases). The base payment and the variable payment are thus highly integrated (Mechanic \& Altman, 2009; Chernew et al., 2011; Song et al., 2012; Song, 2014). Gesundes Kinzigtal

Gesundes Kinzigtal is a population-based integrated care approach in the Kinzigtal region, Germany. Providers are (financially) accountable for care across all health service sectors and indications (e.g. active health promotion for the elderly, disease management programs for chronic conditions and patient university programs). The target population consists of all individuals who are insured by one of the two sickness funds in the region. Key to this initiative is the shared health gain approach by means of a shared savings contract (i.e. financial goals are realised if actual costs in the region increase at a lower rate than the German norm costs). The base payment is a global budget and equals the costs of the German risk-adjusted standard (i.e. the norm costs within the context of the risk-equalisation system). Quality is stimulated by means of a P4P-program (Hildebrandt et al., 2010; Hildebrandt et al., 2012; Busse \& Stahl, 2014).
\end{abstract}

Henceforth, we focus on the first component of a theoretically preferred VBP - the base payment for two reasons. First, the design of the second component - the variable payment - has already been extensively discussed in the literature (for an overview, see Eijkenaar, 2013; Milstein \& Schreyögg, 2016). Second, as argued above, the base payment typically comprises the majority of providers' revenues, underlining the importance of carefully designing the implicit incentives generated by this component.

\title{
4.2 Five key features of a theoretically preferred base payment
}

Below, we explain which key features of a theoretically preferred base payment are required to stimulate value in a broad sense. Based on a synthesis of the findings of key studies conducted in 
the field of health services research, health economics, contract theory and the general economic theory on incentive design, we conclude that the base payment should preferably be paid (1) to a multidisciplinary provider group for delivering (2) a cohesive set of care activities to a predefined population. In addition, the base payment should (3) be fixed, (4) be adjusted for the population's risk profile and (5) include risk-mitigating measures. We acknowledge that these five key features are interrelated (e.g. for the provision of a comprehensive set of care activities a multidisciplinary provider group is required).

\subsubsection{Multidisciplinary provider group}

To encourage well-coordinated care, the base payment should jointly remunerate multidisciplinary groups of providers who have agreed to work together as an 'accountable group' for the delivery of a cohesive set of care activities. Depending on the exact nature of the care activities, these groups may consist of different types of physicians (e.g. primary care physicians or medical specialists), other health care professionals (e.g. nurses or physiotherapists) and various care facilities (e.g. specialty hospitals or rehabilitation centres).

Financial barriers between separately paid providers are removed once a single, integrated payment for a provider group is introduced. Such an integrated payment to a provider team is expected to encourage multidisciplinary cooperation and collaboration, fostering greater (crossspecialty) coordination and increasing active provider engagement in improvements across the whole care path (Anderson \& Weller, 1999; Berenson, 2010; Burwell, 2015; Mehrotra \& Hussey, 2015). This is of relevance particularly for the increasing number of individuals with multiple coexisting (chronic) health problems who will likely benefit from well-coordinated, integrated care (DeGruy \& Etz, 2010; Pollack et al., 2012; Leijten et al., 2017). In addition, paying a provider group instead of individual providers is likely to result in more flexibility in the use of resources (Mechanic \& Altman, 2009; Miller, 2009; Cutler \& Ghosh, 2012; Tsiachristas et al., 2013). Another advantage is that the financial risk that is associated with VBP is pooled. This may prevent individual providers from being confronted with excessive financial risk and may reduce incentives for undesired behaviour (Anderson \& Weller, 1999; Gaynor et al., 2004; Vermaas, 2006; Frakt \& Mayes, 2012).

Group-based incentives require a certain entity that contracts with the purchaser and receives the payment on behalf of the provider group. This 'main contracting entity' administers the payment and is responsible for the organisation, coordination and (possibly) the delivery of care activities and employs or subcontracts other providers (Anderson \& Weller, 1999). The main contractor thus initially bears the financial risk and has to divide the pain and gain among the group members. Entities such as ACOs, health maintenance organisations (HMOs) and hospitals might qualify for this role because of their size and level of professionalism. To pass the incentives along from the group to the individual providers, a transparent payment distribution mechanism needs to be developed; it has to be decided 'who is getting paid, how much, for doing what' (Frølich et al., 2007). For instance, distribution can be in proportion to the provider's share of the target population or the provider's contribution to the group's performance (Olson, 1965; Gaynor et al., 2004; Conrad, 2015).

\subsubsection{Cohesive set of care activities for a predefined population}

To encourage cost-effective prevention, the base payment should remunerate a provider group for the provision of a cohesive set of (preventive) care activities to a predefined population of individuals. From a theoretical perspective, VBP ideally involves 'whole-person accountability'. Key to such an approach is that the payment is not disease-specific but person-centred and holistic. The payment covers all relevant health services given a person's needs. An evident set of care activities that is covered by the payment is (virtually) the full continuum of services included in the relevant benefit package in place. For instance, if a provider group accepts whole-person accountability for a target population of diabetics, the provider group is not only responsible for 
all diabetes-related care but for all care services that the diabetics in the target population might need, within limitations of the relevant benefit package covered by the health plan or other third party payer. The target population may consist of any defined set of individuals, including those not currently in need of care (Kindig, 2007).

Whole-person accountability triggers incentives for health promotion and prevention because prevention is often more effective and cheaper than cure. The more a provider group improves the health of the population, the greater the financial gain (Sharfstein, 2016). Stimulating preventive efforts is of great importance, since the causes of many health problems lie in individual behaviour (e.g. smoking and unhealthy diet) and the current system does not effectively promote healthy behaviour (Berwick et al., 2008; Casalino et al., 2015). Another advantage of a wholeperson accountability approach is that effective long-term management of chronic diseases (e.g. delaying the progression of diseases and preventing exacerbations) is stimulated (Berenson, 2010; McClellan et al., 2013; Conrad, 2015). In addition, cost-shifting becomes more difficult once the payment applies to a broad set of care activities and is even impossible if the payment applies to all care services (Sood, 2011; Busse \& Stahl, 2014). The provision of unnecessary services is expected to gradually be phased out (Gaynor et al., 2004; McClellan et al., 2013). Finally, the risk of double payment for the same services decreases. Double payment is plausible in particular for patients with comorbidity and if services are paid for through different systems (Hussey et al., 2011; EIB, 2012; Ridgely et al., 2014).

Four characteristics can be used to delineate the target population: (1) individual characteristics (e.g. age or diagnoses), (2) geographical catchment areas (e.g. region or ZIP-codes), (3) provider affiliation (e.g. enrolment in a GP practice or retrospective assignment to a provider based on actual utilisation) and (4) purchaser affiliation (e.g. having an insurance policy with a specific insurer). The characteristics are not mutually exclusive. Under the AQC (Box 1), the target population consists of individuals who are below 65 years of age, live in Massachusetts, are registered with a primary health care provider, and have an HMO or preferred provider organisation (PPO) insurance policy from BCBS (Mechanic \& Altman, 2009; Chernew et al., 2011; Song et al., 2012; Song, 2014). Assignment of the target population to the provider group for the coming year can be done prospectively (e.g. based on enrolment with affiliated primary care physicians, or on health care utilisation in the prior year) or retrospectively (e.g. based on the plurality of utilisation in the completed year). In case of prospective assignment, provider groups know beforehand for whom they are responsible in the coming year, enabling providers to proactively reach out to and improve care for their target population (Lewis et al., 2013). A potential advantage of retrospective assignment is that it stimulates providers to manage costs and quality for all of their patients, instead of just the assigned population. However, professional ethics may effectively prevent that - under prospective assignment - providers will actually distinguish between assigned and unassigned patients in terms of (the quality of) provided services. Under the AQC, assignment is done prospectively, while under the MSSP a retrospective form is used (Box 1).

\subsubsection{Fixed payment for a defined period of time}

To encourage cost-conscious behaviour and cost-effective innovation, the base payment should be fixed for a defined period of time, implying that there is no link with actual costs (Anderson \& Weller, 1999; Jegers et al., 2002). Such a method implies that (some of) the financial risk is transferred from the purchaser to the provider. The financial result is retrospectively determined by the difference between actual expenses and the prospectively defined, fixed payment ('reconciliation').

A fixed payment for a defined period of time is theoretically preferred over a variable payment because of the high potential for cost-conscious behaviour and cost-effective innovation. Because marginal benefits are zero, providers are stimulated to reduce costs and to reconsider the full care process (Jegers et al., 2002; Miller, 2009; Cutler \& Gosh, 2012; Conrad et al., 2014; Conrad, 2015). 
Critically assessing care processes might also uncover room for substitution of relatively expensive for relatively inexpensive services or providers (Casalino, 2001). In addition, because the payment can be flexibly deployed, more attention can be paid to cost-effective, creative management of care (Anderson \& Weller, 1999; McConnell et al., 2014). Note, however, that a fixed payment for a defined period of time also is a main feature of traditional capitation that was heavily criticised in the past for, amongst other things, triggering care rationing and threatening patient choice (Porter \& Kaplan, 2016). These drawbacks from traditional capitation can be addressed by adding a variable payment component guaranteeing high-quality care (see Section 4.1), by adopting adequate risk adjustment (see Section 4.2.4.) and by including arrangements to mitigate excessive financial risk (see Section 4.2.5).

Below, three design issues of a fixed payment for a defined period of time are discussed: setting the payment level, multiyear contracts and risk transfer.

4.2.3.1 Setting the payment level In general, three methods for setting the fixed payment level can be discerned. A first method is based on historical expenses (Douven et al., 2015; Rose et al., 2016). An advantage of this approach is that calculation is relatively straightforward. However, because the payment level is based on prior expenses, past inefficiencies are 'buried' in the payment (Newhouse et al., 1997; Berenson, 2010). Moreover, providers have a perverse incentive to increase expenses in the years prior to the onset of the contract, in order to build up the historical expenses that lie at the basis of the payment level (Berenson, 2010; Chernew et al., 2011; Douven et al., 2015). A second approach is basing the payment on average expenses, for instance per relevant peer group or region (Newhouse et al., 1997; Ellis \& McGuire, 1988). An advantage is that the payment is relatively easy to calculate and providers with higher than average expenses due to inefficiency are stimulated to reassess their delivery processes. However, providers with higher than average expenses as a result of a disproportionate amount of high-risk individuals in the target population are disadvantaged (Rose et al., 2016). In this case, the payment level can be considered as unfair and inaccurate, calling for appropriate risk adjustment (Section 4.2.4). A third option is to base the payment on acceptable expenses (Newhouse et al., 1997). In this case, the payment is set at a level that is sufficient to cover only those expenses generated in delivering medically necessary, cost-effective care (Van de Ven \& Ellis, 2000). Although this approach seems theoretically preferred, it is difficult to implement in practice, since selecting the 'right' care activities and putting a price upon each service is disputable or likely to be unfeasible. Regardless of the chosen method for setting the payment level, the absolute price is clearly of relevance too. The payment should at least be sufficient to cover (potential) resource costs and to make the provision of high-value care worthwhile for providers.

4.2.3.2 Multiyear contracts Contracts in which the fixed payment level is specified can be expected to be incomplete on a range of variables due to the multitasking problem (Maskin \& Tirole, 1999; Hart, 2003). In the case of incomplete contracts, a certain level of mutual trust between the purchaser and the provider group is vital. Multiyear contracts are a sign of mutual trust and prevent costly effort on 'overwriting' complex, short-term contracts (Marques \& Berg, 2011). Microeconomic theory suggests that long-term contracts produce more favourable effects as compared to short-term contracts. A multiyear contract is likely to stimulate innovation and prevention because, over the longer term, providers are more likely to reap the financial benefits of their investments (Silberberg, 1990; Christianson \& Conrad, 2011; Shortell, 2013). On the other hand, providers and purchasers may also be hesitant to conclude multiyear payment contracts because of the concern about being locked into the contract. This calls for a certain level of flexibility in the contract to be able to adjust for inflation and unforeseen events (Chernew et al., 2011; Rose et al., 2016). In practice, multiyear VBP contracts have evolved, such as the five-year AQC contracts (Box 1). 
4.2.3.3 Risk transfer An important consequence of a fixed base payment for a defined period of time is that (some of) the financial risk is transferred from the purchaser to the accountable provider group. Two types of risk may be transferred: insurance risk and performance risk. Insurance risk is the risk that is typically borne by the purchaser and concerns the random variation around the mean health care expenses. Performance risk is the systematic variation around the mean expected health care expenses due to providers acting as imperfect agents. This risk can be influenced by providers, as it directly relates to the clinical skills and the choices made by the provider (Vermaas, 2006; De Brantes \& Rastogi, 2008; Miller, 2009; Berenson, 2010).

Ideally, only performance risk is transferred to the provider group, whereas insurance risk remains with the purchaser (Porter \& Kaplan, 2016). After all, it is the typical function of a purchaser to deal with random variation by pooling risks, and transforming providers into insurers is not the goal of VBP. Because the target population of a provider group is likely to be smaller than the total number of individuals the purchaser is responsible for, the conditions of the law of the large numbers for effective risk pooling might not be sufficiently fulfilled. Therefore, the provider group might face substantial financial risk due to large random variation from the statistically expected result (Christianson \& Conrad, 2011; Van de Ven, 2014). In comparison to purchasers, providers have limited financial means at their disposal to compensate for this random variation. Transferring insurance risk to providers could encourage risk selection (Section 4.2.4) and, in extremis, providers might go bankrupt (Anderson \& Weller, 1999; Vermaas, 2006).

Unfortunately, it is practically unfeasible to split insurance risk and performance risk (Vermaas, 2006). Often, unravelling the extent to which health outcomes are the result of chance or of providers acting as (im)perfect agents is virtually impossible. For instance, a lower incidence of diabetes-related health problems in the target population could be the result of a decrease of the number of individuals with obesity due to a successful government campaign to improve lifestyle, but could also stem from a provider's successful effort in monitoring blood glucose levels. The first explanation is not necessarily linked to the provider's performance, while the second cause refers to the provider acting as a good agent. While risk-splitting is thus not possible, distributing the financial risk among providers and the purchaser in such a way that providers bear some, but not all, of the risk may be a viable option (Frakt \& Mayes, 2012).

\subsubsection{Risk adjustment}

To prevent undesired behaviour that may thwart key-value dimensions, the base payment should be risk-adjusted. If the payment is not corrected for systematic variation in expenses due to differences in risk characteristics of the target population, incentives for risk selection evolve because then the financial result is partly determined by the risk composition of the population, rather than a mark of achievement. Providers would be unfairly penalised financially if they are responsible for a disproportionate amount of high-risk individuals rather than low-risk individuals. In this case, providers have a financial incentive for risk selection which is the practice of attracting low-risk individuals for which the payment exceeds expected expenses and/or avoiding high-risk individuals for which the opposite holds (Iezzoni, 2003; Sood, 2011; Rose et al., 2016). Risk selection is undesired because it may jeopardise quality, equal access and efficiency (Welch, 1999; Jegers et al., 2002; Barros, 2003). Several empirical studies provide evidence of risk selection by capitated provider groups (Newhouse \& Byrne, 1988; Frank \& Lave, 1989; Newhouse, 1989; Cutler \& Zeckhauser, 1998; Altman et al., 2000; Dranove et al., 2003; Chang et al., 2012; Hsieh et al., 2016).

In case of fixed payments, provider groups may experience incentives for risk selection. Because of the relatively small size of target populations a small number of high-risk individuals may have a large impact on the global budget. Providers are in the position to be successful in risk selection. First, providers are particularly well equipped to effectively identify low-risk and high-risk individuals because they have information about the health status of their target 
population and they are professionally trained to assess this type of information. Second, providers have subtle tools for risk selection. For instance, a provider might advise a high-risk patient to switch to a different provider by suggesting that he or she would be better served elsewhere (Folland et al., 2013). Non-financial restraints, such as peer review and professional ethics, may however counteract incentives for providers to engage in risk selection (Eggleston, 2000).

With risk adjustment predictable, systematic variation in expenses as a result of differences in risk characteristics of the population is recognised and accounted for. In this way, risk adjustment contributes to a fair allocation of payments and ensures that providers are willing to accept and serve high-risk individuals. Ideally, risk adjustment creates a level playing field for providers (Anderson \& Weller, 1999; Iezzoni, 2003; McGuire, 2011; Ash \& Ellis, 2012; Omachi et al., 2013; Brilleman et al., 2014; Rose et al., 2016). In Gesundes Kinzigtal, the base payment equals the normative cost-level calculated using the German risk-adjustment model for health insurers, and ACO and AQC models use population risk-score software to adjust for differences in risk characteristics of the target population (Box 1). It is an interesting question to what extent existing risk-adjustment models - most of which were originally developed to adjust capitation payments for insurers - can be (adequately) used to adjust provider payments, taking account of differences between provider and insurer payment regarding incentives and tools for risk selection.

\subsubsection{Arrangements to limit excessive financial risk}

To prevent undesired behaviour that may thwart key-value dimensions, the base payment should include arrangements that effectively mitigate excessive financial risk for providers. As discussed before, providers accepting VBP share financial risk with the purchaser. Risk adjustment accounts for systematic, predictable variation in expenses. However, the majority of between-person variance is random and unpredictable (Van Vliet, 1992; Newhouse, 1996; Ellis \& McGuire, 2007). This implies that, even in the unlikely case of perfect risk adjustment, providers still face significant residual financial risk. To protect providers against excessive financial risk, additional approaches to mitigate this risk are likely to be required. In principle, these arrangements are focussed on protecting providers against large, unpredictable, random losses (i.e. insurance risk). However, such arrangements could also include protection against predictable and systematic risk that is, for whatever reason, not corrected for by a risk-adjustment model. Note that risk-mitigating arrangements could be used not only to limit but also to (gradually) expand the financial risk a provider runs. Below, we elaborate on two main parameters that can be simultaneously used to bring the financial risk to appropriate levels.

4.2.5.1 Type of risk sharing Two main types of risk contracts can be distinguished. Under a one-sided risk contract, providers that keep expenses below the global payment share in the savings with the purchaser. An advantage is that providers can get familiar to accepting financial 'risk' without sharing in the losses and, keeping all else constant, have less incentives for undesired behaviour such as risk selection (Berwick, 2011). Under a two-sided risk contract, providers share in the savings, but also in the losses if expenses exceed the global budget. Providers accepting two-sided risk qualify for higher shared savings rates (Berwick, 2011; Rose et al., 2016). Theoretical and empirical evidence from the field of behavioural economics has shown that individuals tend to prefer avoiding losses to achieving equivalent gains (Kahneman \& Tversky, 1979; McNeil et al., 1982), suggesting that a two-sided risk contract provides stronger incentives for value than a contract that includes rewards only (Berenson, 2010). However, incentives for undesired behaviour increase under a two-sided risk contract (assuming imperfect risk adjustment). In the MSSP, ACOs can opt for a one-sided or a two- 
sided risk contract while they are in their first two contract periods. After this period, they can only accept a two-sided risk contract (Berwick, 2011; Rose et al., 2016).

In addition to one- and two-sided risk contracts, risk corridors and reinsurance can be used to bring financial risk to the appropriate level. Risk corridors protect against cumulative losses, because losses and gains are limited beyond a predefined acceptable range (Layton et al., 2016). Reinsurance can be defined as 'the insurance of contractual liabilities incurred under contracts of direct insurance or reinsurance' (Carter, 1983: 4). In the case of VBP, reinsurance would imply that providers are retrospectively reimbursed by the purchaser for some or all of the expenses of specific individuals from their population, based on prospectively determined conditions. Under the AQC, for example providers can buy reinsurance from BCBS or an external entity (Chernew et al., 2011). A variety of non-mutually exclusive reinsurance techniques exist, such as stop-loss contracts, proportional risk sharing and outlier risk sharing (e.g. Carter, 1983; Von Eije, 1989; Bovbjerg, 1992; Van Barneveld et al., 1998; Anderson \& Weller, 1999; Vermaas, 2006; Miller, 2009).

4.2.5.2 Extent of risk sharing Under VBP, the main contractor (i.e. provider group) shares the financial risk with the purchaser. Thus, the provider group is typically liable for less than $100 \%$ of the financial result (Vermaas, 2006; Frakt \& Mayes, 2012). The risk rate (i.e. the share of savings/ losses the provider group is accountable for) should not be set too high in order to keep the risk manageable for the provider group and to prevent (strong) incentives for risk selection in the case of imperfect risk adjustment. However, this rate should not be set too low either, because then the incentives lack power to actually affect provider's behaviour (Laffont \& Tirole, 1993; Gaynor et al., 2004).

The risk rate ideally depends on several variables. A first factor concerns the size of the target population. Ceteris paribus, if the size of the population increases, the payment is expected to gain in stability due to the law of the large numbers, allowing higher risk rates. Second, it seems natural to increase the risk rate for primary relative to secondary care if a primary care group acts as main contractor, while the opposite may be preferred if a hospital accepts this role. Third, the diminishing marginal utility of income might be taken into account (Conrad \& Perry, 2009). Under the AQC, the risk borne by the different groups of providers ranges from $50 \%$ to $100 \%$ and is periodically (re)negotiated between the provider group and BCBS (Chernew et al., 2011).

In addition to the risk rate, carve-outs can be used to influence the extent of risk sharing. Carve-outs mitigate the financial risk for providers by placing a portion of the risk outside the payment and contracting separately for this risk (Frank \& McGuire, 1998). For VBP, this would imply that certain services, medical conditions or populations are excluded from the contract and are paid for on a separate basis, such as FFS. Consequently, providers are protected against the associated high expenses of these services, conditions or populations and the high costs that are associated with acquiring the needed expertise (Frank \& McGuire, 1998). Examples of possible carve-outs are intensive care, organ transplantation, mental health or cancer care. Carve-outs may also be required if whole-person accountability is not (instantly) feasible from a practical point of view or for those care services for which risk adjustment is not or insufficiently attainable; carve-outs can be used as an interim measure to (temporarily) exclude certain care types from the payment.

\section{Trade-offs in the operationalisation of the base payment}

In Section 4, a theoretically preferred VBP design was discussed. We explained how the largest component of VBP - the base payment - should preferably be designed to incentivise value. When it comes to the practical operationalisation of the base payment, several inherent trade-offs arise, implying that no 'one size fits all' design exists that can optimally incentivise all key-value 
dimensions simultaneously. The practical operationalisation of the base payment and the extent to which the different value dimensions are incentivised, depend on three determinants: (1) compatibility of incentives, (2) preferences and (3) context. Below, these determinants are briefly discussed and illustrated.

\subsection{Compatibility of incentives}

Theory predicts that several key features of the base payment are likely to conflict to a certain extent. For instance, regarding the optimal composition and size of the provider group, stronger incentives for well-coordinated care must be traded-off against weaker incentives for costconscious behaviour. In order to be able to deliver (virtually) the full continuum of care and realise well-coordinated care, the provider group will have to be composed of many different types of providers. But, as the composition becomes more diverse, the size of the provider group is likely to increase as well. Consequently, the financial risk that is associated with VBP is necessarily spread over more providers within the group, reducing the financial incentives for individual providers and increasing incentives for free-rider behaviour (Gaynor \& Gertler, 1995; Gaynor et al., 2004; Town et al., 2004; Conrad, 2015).

Another example of a practical decision involving trade-offs is about the comprehensiveness of the set of activities a provider group is responsible for. If the payment covers a broader set of care activities, the payment moves towards 'whole-person accountability' and incentives for health promotion and (primary) prevention become stronger. However, given that perfect risk adjustment is practically unfeasible, a more comprehensive set of activities will also increase the incentives for risk selection. Hence, stronger incentives for cost-effective prevention should be weighed against stronger incentives for risk selection.

\subsection{Preferences}

In trading-off the different value dimensions, decision-makers should carefully weigh preferences for each dimension, taking full account of relevant (societal) interests. For instance, if in a country health care expenses are considered to be at an acceptable level, while quality is considered to be suboptimal, decision-makers may attach greater importance to incentives for highquality care and compromise on the incentives for cost-conscious behaviour (under the assumption that higher quality is associated with higher expenses). In this case, the share of the variable payment may be expanded, whereas the financial risk for providers may be reduced. Alternatively, a country with escalating health care expenses and an inefficient health care system may choose to intensify incentives for cost-conscious behaviour by expanding the financial risk for providers, while accepting the possible negative consequences in terms of stronger incentives for risk selection.

\subsection{Context}

The context of implementation can have a major impact on the practical operationalisation of the base payment, implying that VBP should be structured in relation to the circumstances of time and place (Conrad et al., 2016). The following four examples illustrate this. First, if limited individual-level data on population risk characteristics are routinely available, a base payment that requires sophisticated risk adjustment is unlikely to be practically feasible. Second, in a setting where providers still predominantly work in monodisciplinary 'silos', it might be problematic to find provider groups that are willing and able to accept whole-person accountability. Third, in a setting in which the IT-infrastructure is underdeveloped, it is unlikely that a multidisciplinary provider group is effectively able to share the information required to realise wellorchestrated, integrated care for the target population (Miller, 2009; Berwick, 2011). Fourth, expanding the size and scope of providers groups covered by VBP may also affect market 
concentration and therefore may reduce consumer choice and workable competition. Therefore, in countries with a competitive health care system, the optimal size and scope of provider groups covered by VBP may be smaller than in countries with a more centralised health care system.

\section{Concluding remarks}

This paper has provided a conceptual framework of key components and design features of a theoretically preferred VBP method. We consider a provider payment method 'value-based' if it stimulates value in a broad sense, that is if it offers incentives for: (1) high-quality care, (2) costconscious behaviour, (3) well-coordinated care, (4) cost-effective innovation and (5) costeffective prevention.

To our knowledge, this is the first paper in the provider payment literature with a prime focus on the design of such a VBP method, and in particular of arguably the most important component thereof: the base payment. Based on a synthesis of existing literature from a variety of fields, this paper provides insight in the contours of a theoretically preferred VBP method.

The main contribution of this paper is twofold. Inspired by the societal debate on what stakeholders in health care should ideally strive for, as well as by existing definitions of value, we first described and further specified the concept of value, facilitating the specification of requirements in the design of VBP. We conclude that, in this respect, value is ideally conceptualised as a multifaceted concept, comprising not only high quality of care at the lowest possible costs but also efficient cooperation, innovation and health promotion. Second, starting from these value dimensions, we derived various design features of a theoretically preferred VBP model. We conclude that in order to stimulate value in a broad sense, the payment should consist of two main components that must be carefully designed. The first component is a risk-adjusted global base payment with risk-sharing elements paid to a multidisciplinary provider group for the provision of (virtually) the full continuum of care to a certain population. The second component is a relatively low-powered variable payment that explicitly rewards aspects of value that can be adequately measured.

Although a well-designed VBP is clearly a necessary condition for realising value-based health care, we acknowledge that it is unlikely to be a sufficient condition. Non-financial mechanisms as well as organisational structures may be at least as important (Robinson, 2001; Christianson \& Conrad, 2011; Phipps-Taylor \& Shortell, 2016). Furthermore, as explained above, the practical operationalisation and implementation of a well-designed VBP model should not be underestimated and be well tailored to the specific context. Nevertheless, several innovative payment initiatives in practice already come quite close to the theoretically preferred VBP-design described in this paper, indicating that this design can actually be implemented in various contexts. An interesting direction for future research would be gaining more insight in how a two-component model as described in this paper can be practically operationalised and successfully implemented given the relevant context, as well as in the short- and long-term effects of introducing such a model on different value dimensions.

Acknowledgements. Our sincere thanks to members and guests of the Risk Adjustment Network meeting 2016 in Berlin, participants of the ESHPM seminar series, Thomas McGuire and two anonymous referees for their helpful comments on earlier drafts of this paper.

\section{References}

Altman D, Cutler DM and Zeckhauser RJ (2000) Enrollee mix, treatment intensity, and cost in competing indemnity and HMO Plans, Journal of Health Economics, 22(1): 23-45.

Anderson GF and Weller WE (1999) Methods of reducing the financial risk of physicians under capitation, Archives of Family Medicine, 8(2): 149-155. 
Ash AS and Ellis RP (2012) Risk-adjusted payment and performance assessment for primary care, Medical Care, 50(8): 643-653.

Barros PP (2003) Cream-skimming, incentives for efficiency and payment method, Journal of Health Economics, 22(3): 419-443.

Berenson RA (2010) Shared Savings Program for accountable care organizations: a bridge to nowhere?, The American Journal of Managed Care, 16(10): 721-726.

Berwick DM (2011) Launching accountable care organizations - the proposed rule for the Medicare Shared Savings Program, The New England Journal of Medicine, 364(16): e32-e35.

Berwick DM, Nolan TW and Whittington J (2008) The triple aim: care, health, and cost, Health Affairs, 27(3): 759-769.

Blomqvist A (1991) The doctor as double agent: information asymmetry, health insurance, and medical care, Journal of Health Economics, 10(4): 411-432.

Bovbjerg RR (1992) Reform of financing for health coverage: what can reinsurance accomplish?, Inquiry, 29(2): $158-175$.

Brilleman SL, Gravelle H, Hollinghurst S, Purdy S, Salisbury C and Windmeijer F (2014) Keep it simple? Predicting primary health care costs with clinical morbidity measures, Journal of Health Economics, 35(100): 109-122.

Burwell SM (2015) Setting value-based payment goals: HHS efforts to improve U.S. health care, The New England Journal of Medicine, 372(10): 897-899.

Busse R and Stahl J (2014) Integrated care experiences and outcomes in Germany, the Netherlands, and England, Health Affairs, 33(9): 1549-1558.

Campbell SM, Reeves D, Kontopantelis E, Sibbald B and Roland M (2009) Effects of pay for performance on the quality of primary care in England, New England Journal of Medicine, 361(4): 368-378.

Carter RL (ed.) (1983) Reinsurance, Dordrecht: Springer Science and Business Media.

Casalino L (2001) Canaries in a coal mine: California physician groups and competition, Health Affairs, 20(4): 97-108.

Casalino LP, Erb N, Joshi MS and Shortell SM (2015) Accountable care organizations and population health organizations, Journal of Health Politics, Policy and Law, 40(4): 819-835.

Chang RE, Lin SP and Aron DC (2012) A pay-for-performance program in Taiwan improved care for some diabetes patients, but doctors may have excluded sicker ones, Health Affairs, 31(1): 93-102.

Chernew ME, Mechanic RE, Landon BE and Safran DG (2011) Private-payer innovation in Massachusetts: the Alternative Quality Contract, Health Affairs, 30(1): 51-61.

Christianson JB and Conrad D (2011) 'Provider payment and incentives', In: S., Glied and P., Smith (eds) The Oxford Handbook of Economics, New York: Oxford University Press. England: The Belknap Press of Harvard University Press, 624-648.

Conrad DA (2015) The theory of value-based payment incentives and their application to health care, Health Services Research, 50(2): 2057-2089.

Conrad DA, Grembowski D, Hernandez SE, Lau B and Marcus-Smith M (2014) Emerging lessons from regional and state innovation in value-based payment reform: balancing collaboration and disruptive innovation, The Milbank Quarterly, 92 (3): 568-623.

Conrad DA and Perry L (2009) Quality-based financial incentives in health care: Can we improve quality by paying for it?, Annual Review of Public Health, 30(1): 357-71.

Conrad DA, Vaughn M, Grembowski D and Marcus-Smith M (2016) Implementing value-based payment reform: a conceptual framework and case examples, Medical Care Research and Review, 73(4): 437-457.

Cutler DM and Ghosh K (2012) The potential for cost savings through bundled episode payments, The New England Journal of Medicine, 366(12): 1075-1077.

Cutler DM and Zeckhauser RJ (1998) 'Adverse selection in health insurance', In: A. M., Garber (ed.) NBER Book Series Frontiers in Health Policy Research, Volume 1, Cambridge, Massachusetts: MIT Press, 1-32.

De Bakker DH, Struijs JN, Baan CB, Raams J, de Wildt JE, Vrijhoef HJM and Schut FT (2012) Early results from adoption of bundled payment for diabetes care in the Netherlands show improvement in care coordination, Health Affairs, 31(2): 426-433.

De Brantes F and Rastogi A (2008) Evidence-informed case rates: paying for safer, more reliable care, Issue brief Commonwealth Fund, 1146(40): 1-13.

De Brantes F, Rosenthal MB and Painter M (2009) Building a bridge from fragmentation to accountability: the Prometheus payment model, The New England Journal of Medicine, 361(11): 1033-1036.

DeGruy FV and Etz RS (2010) Attending to the whole person in the patient-centred medial home: the case for incorporating mental health care, substance abuse care, and health behaviour change, Families, Systems \& Health: The Journal of Collaborative Family Healthcare, 28(4): 298-307.

Donabedian A (1988) The quality of care: How can it be assessed?, The Journal of the American Medical Association, 260 (12): 1743-1748.

Douven R, McGuire TG and McWilliams JM (2015) Avoiding unintended incentives in ACO payment models, Health Affairs, 34(1): 143-149. 
Dranove D, Kessler D, McClellan, M M and Satterthwaite M (2003) Is more information better? The effects of 'report cards' on health care providers, The Journal of Political Economy, 111(3): 555-588.

Eggleston K (2000) Risk selection and optimal health insurance-provider payment systems, The Journal of Risk and Insurance, 67(2): 173-196.

Eggleston K (2005) Multitasking and mixed systems for provider payment, Journal of Health Economics, 24(1): 211-223.

EIB, Evaluatiecommissie Integrale Bekostiging (2012) Eindrapport van de Evaluatiecommissie Integrale Bekostiging. Integrale bekostiging van zorg: werk in uitvoering, Den Haag: Evaluatiecommissie Integrale Bekostiging.

Eijkenaar F (2013) 'Pay-for-Performance for Healthcare Providers: Design, Performance Measurement, and (Unintended) Effects', Doctoral Dissertation, Erasmus University Rotterdam.

Eijkenaar F and Schut FT (2015) Uitkomstenbekostiging in de zorg: een (on)begaanbare weg?, Rotterdam: Erasmus Universiteit Rotterdam.

Ellis RP and McGuire TG (1986) Provider behaviour under prospective reimbursement, Journal of Health Economics, 5(2): 129-151.

Ellis RP and McGuire TG (1988) Insurance principles and the design of prospective payment methods, Journal of Health Economics, 7(3): 215-237.

Ellis RP and McGuire TG (2007) Predictability and predictiveness in health care spending, Journal of Health Economics, 26 (1): $25-48$.

Ellis RP and Miller MM (2008) 'Provider payment methods and incentives', In: H. K., Heggenhougen and S. R., Quah (eds) International Encyclopaedia of Public Health, Amsterdam: Elsevier Inc, 395-402.

Enthoven AC (1988) Theory and Practice of Managed Competition in Health Care Finance, Amsterdam: Elsevier Science.

Epping-Jordan JE, Pruitt SD, Bengoa R and Wagner EH (2004) Improving the quality of health care for chronic conditions, Quality and Safety in Health Care, 13(4): 299-305.

Folland S, Goodman AC and Stano M (2013) The Economics of Health and Health Care, Boston: Pearson Education.

Frakt AB and Mayes R (2012) Beyond capitation: how new payment experiments seek to find the sweet spot in amount of risk providers and payers bear, Health Affairs, 3(9): 1951-1958.

Frank RG and Lave JR (1989) A comparison of hospital responses to reimbursement policies for Medicaid psychiatric patients, The Rand Journal of Economics, 20(4): 588-600.

Frank RG and McGuire TG (1998) The economic functions of carve outs in managed care, The American Journal of Managed Care, 4(25): 31-39.

Frølich A, Talavera JA, Broadhead P and Dudley RA (2007) A behavioral model of clinician responses to incentives to improve quality, Health Policy, 80(1): 179-193.

Gaynor M and Gertler P (1995) Moral hazard and risk spreading in partnerships, The RAND Journal of Economics, 26(4): 591-613.

Gaynor M, Rebitzer JB and Taylor LJ (2004) Physician incentives in health maintenance organizations, The Journal of Political Economy, 112(4): 915-931.

Glickman SW, Ou F, DeLong ER, Roe M, Lytle B, Mulgund J, Rumsfeld J, Gibler W, Ohman EM, Schulman K and Peterson ED (2007) Pay for performance, quality of care, and outcomes in acute myocardial infarction, Journal of the American Medical Association, 297(21): 2373-2380.

Hart O (2003) Incomplete contracts and public ownership: remarks and an application to public-private partnerships, The Economic Journal, 113(486): C69-C76.

Hildebrandt H, Hermann C, Knittel R, Richter-Reichhelm M, Siegel A and Witzenrath WS (2010) Gesundes Kinzigtal Integrated Care: improving population health by a shared health gain approach and a shared savings contract, International Journal of Integrated Care, 10(2): 1-15.

Hildebrandt H, Schulte T and Stunder B (2012) Triple aim in Kinzigtal, Germany: improving population health, integrating health care and reducing costs of care - lessons for the UK?, Journal of Integrated Care, 20(4): 205-222.

Hsieh HM, Tsai SL, Mau LW and Chiu HC (2016) Effects of changes in diabetes pay-for-performance incentive designs on patient risk selection, Health Services Research, 51(2): 667-686.

Holmstrom B and Milgrom P (1991) Multitask principal-agent analyses: incentive contracts, asset ownership, and job design, Journal of Law, Economics, and Organization, 7(1): 24-52.

Hussey PS, Ridgely MS and Rosenthal MB (2011) The PROMETHEUS bundled payment experiment: slow start shows problems in implementing new payment models, Health Affairs, 30(11): 2116-2124.

Iezzoni LI (ed.) (2003) Risk Adjustment for Measuring Health Care Outcomes, Chicago: Health Administration Press.

IOM, Institute of Medicine (2001) Crossing the Quality Chasm: A New Health System for the 21st Century, Washington DC: National Academies Press.

Jegers M, Kesteloot K, de Graeve D and Gilles W (2002) A typology for provider payment systems in health care, Health Policy, 60(3): 255-273.

Jensen MC and Meckling WH (1976) Theory of the firm: managerial behaviour, agency costs and ownership structure, Journal of Financial Economics, 3(4): 305-360.

Kahneman D and Tversky A (1979) Prospect theory: an analysis of decision under risk, Econometrica, 47(2): $263-292$. 
Kindig DA (2007) Understanding population health terminology, The Milbank Quarterly, 85(1): 139-161.

Laffont J and Martimort D (2002) The Theory of Incentives: The Principal-Agent Model, Princeton: Princeton University Press.

Laffont J and Tirole J (1993) A Theory of Incentives in Procurement and Regulation, Cambridge, Massachusetts: MIT Press.

Layton TJ, McGuire TG and Sinaiko AD (2016) Risk corridors and reinsurance in health insurance marketplaces: insurance for insurers, American Journal of Health Economics, 2(1): 66-95.

Leijten FRM, Struckmann V, van Ginneken E, Czypionka T, Krauss M, Reiss M, Tsiachristas A, Boland M, de Bont A, Bal R, Busse R and Rutten-van Mölken M (2017) 'The SELFIE framework for integrated care for multi-morbidity: development and description', Health Policy, (in press). https://doi.org/10.1016/j.healthpol.2017.06.002.

Lewis VA, McGlurg AB, Smith J, Fisher ES and Bynum JPW (2013) Attributing patients to accountable care organizations: performance year approach aligns stakeholders' interests, Health Affairs, 32(3): 587-595.

Lindenauer PK, Remus D, Roman S, Rothberg MB, Benjamin EM, Ma A and Bratzler DW (2007) Public reporting and pay for performance in hospital quality improvement, The New England Journal of Medicine, 356(5): 486-496.

Marmor T, Oberlander J and White J (2011) Medicare and the federal budget: misdiagnosed problems, inadequate solutions, Journal of Policy Analysis and Management, 30(4): 928-934.

Marques RC and Berg S (2011) Public-private partnership contracts: a tale of two cities with different contractual arrangements, Public Administration, 89(4): 1585-1603.

Maskin E and Tirole J (1999) Unforeseen contingencies and incomplete contracts, Review of Economic Studies, 66(1): 83-114.

McClellan M, Kent J, Beales S, Macdonell M, Thoumi A and Shuttleworth A (2013) Focusing Accountability on the Outcomes that Matter. Retrieved from http://www.wish-qatar.org/app/media/384 [28 January 2017].

McConnell KJ, Chang AM, Cohen DJ, Wallace N, Chernew ME, Kautz G, McCarty D, McFarland B, Wright B and Smith J (2014) Oregon's Medicaid transformation: an innovative approach to holding a health system accountable for spending growth, Healthcare, 2(3): 163-167.

McGuire TG (2000) 'Physician agency', In: A. J., Culyer and J. P., Newhouse (eds) Handbook of Health Economics, Amsterdam: Elsevier Science B.V., 461-536.

McGuire TG (2011) 'Physician agency and payment for primary medical care', In: S., Glied and P., Smith (eds) The Oxford Handbook of Health Economics, New York: Oxford University Press Inc, 602-623.

McNeil BJ, Pauker SJ, Sox HC Jr and Tversky A (1982) On the elicitation of preferences for alternative therapies, The New England Journal of Medicine, 306(21): 1259-1262.

McWilliams JM, Chernew EC, Landon BE and Schwartz AL (2015) Performance differences in year 1 of Pioneer Accountable Care Organizations, The New England Journal of Medicine, 372(20): 1927-1936.

Mechanic RE and Altman SH (2009) Payment reform options: episode payment is a good place to start, Health Affairs, 28 (2): w286-w71.

Mechanic R and Tompkins C (2012) Lessons learned preparing for Medicare bundled payments, The New England Journal of Medicine, 367(20): 1873-1875.

Mehrotra A and Hussey P (2015) Including physicians in bundled hospital care payments: time to revisit an old idea?, The Journal of the American Medical Association, 313(19): 1907-1908.

Mendelson A, Kondo K, Damberg C, Low A, Motu' apuaka M, Freeman M, O’Neil M, Relevo R and Kansagara D (2017) The effects of pay-for-performance programs on health, health care use, and processes of care: a systematic review, Annals of Internal Medicine, 166(5): 341-353.

Miller HD (2009) From volume to value: better ways to pay for health care, Health Affairs, 28(5): 1418-1428.

Milstein R and Schreyögg J (2016) Pay for performance in the inpatient sector: a review of 34 P4P programs in 14 OECD countries, Health Policy, 120(10): 1125-1140.

Mullen KJ, Frank RG and Rosenthal M (2010) Can you get what you pay for? Pay-for-performance and the quality of healthcare providers, RAND Journal of Economics, 41(1): 64-91.

Newhouse JP (1996) Reimbursing health plans and health providers: efficiency in production versus selection, Journal of Economic Literature, 34(3): 1236-1263.

Newhouse JP (1989) Do unprofitable patients face access problems?, Health Care Financing Review, 11(2): $33-42$.

Newhouse JP, Buntin MB and Chapman JD (1997) Risk adjustment and Medicare: taking a closer look, Health Affairs, 16 (5): 26-43.

Newhouse JP and Byrne DJ (1988) Did Medicare's prospective payment cause lengths of stay to fall?, Journal of Health Economics, 7(4): 413-416.

Olson M (1965) The Logic of Collective Action: Public Goods and the Theory of Groups, Cambridge, Massachusetts: Harvard University Press.

Omachi TA, Gregorich SE, Eisner MD, Penaloza RA, Tolstykh IV, Yelin EH, Iribarren C, Dudley RA and Blanc PD (2013) Risk adjustment for health care financing in chronic disease: What are we missing by failing to account for disease severity?, Medical Care, 51(8): 740-747. 
Pham HH, Ginsburg PB, Lake TK and Maxfield MM (2010) 'Episode-Based Payments: Charting a Course for Health Care Payment Reform', Report No. Policy Analysis 1. Retrieved from National Institute for Health Care Reform website: http:// nihcr.org/wp-content/uploads/2015/03/NIHCR_Policy_Analysis_No._1.pdf.

Phipps-Taylor M and Shortell SM (2016) More than money: motivating physician behavior change in accountable care organizations, The Milbank Quarterly, 94(4): 832-861.

Pollack DA, Raney LE and Vanderlip ER (2012) 'Integrated care and psychiatrists', In: H. L., McQuistion, W. E., Sowers, J. M., Ranz and J. M., Feldman (eds) Handbook of Community Psychiatry., New York: Springer, 163-175.

Porter ME (2009) A strategy for health care reform: toward a value-based system, The New England Journal of Medicine, 361 (2): 109-112.

Porter ME (2010) What is value in health care?, The New England Journal of Medicine, 363(26): 2477-2481.

Porter ME and Kaplan MS (2016) How to pay for health care?, Harvard Business Review, 94(7/8): 88-102.

Porter ME and Teisberg EO (2006) Redefining Health Care: Creating Value-Based Competition on Results, Boston: Harvard Business Review.

Prendergast C (1999) The provision of incentives in firms, Journal of Economic Literature, 37(1): 7-63.

Pronovost PJ (2013) Enhancing physicians' use of clinical guidelines, The Journal of the American Medical Association, 310 (23): 2501-2502.

Richardson J (1981) 'The inducement hypothesis: that doctors generate demand for their own services', In: J., van der Graag and M., Perlmand (eds) Health, Economics and Health Economics, Amsterdam: North-Holland Publishing Company, 189-214.

Ridgely MS, de Vries D, Bozic KJ and Hussey PS (2014) Bundled payment fails to gain a foothold in California: the experiment of the IHA bundled payment demonstration, Health Affairs, 33(8): 1345-1352.

Robinson JC (2001) Theory and practice in design of physician payment incentives, Milbank Quarterly, 79(2): 149-177.

Rose S, Zaslavsky AM and McWilliams JM (2016) Variation in accountable care organization spending and sensitivity to risk adjustment: implications for benchmarking, Health Affairs, 35(3): 440-448.

Ross SA (1973) The economic theory of agency: the principal's problem, American Economic Review, 62(2): 134-139.

Ryan AM, Shortell SM, Ramsay PP and Casalino LP (2015) Salary and quality compensation for physician practices participating in accountable care organizations, Annals of Family Medicine, 13(4): 321-324.

Sharfstein JM (2016) Global budgets for rural hospitals, The Milbank Quarterly, 94(2): 255-259.

Shortell SM (2013) Bridging the divide between health and health care, The Journal of the American Medical Association, 309(11): 1121-1122.

Song. Z (2014) 'Payment Reform in Massachusetts: Health Care Spending and Quality in Accountable Care Organizations 4 Years into Global Payment', Doctoral Dissertation, Harvard Medical School.

Song Z, Safran DB, Landon BE, Landrum MB, He Y, Mechanic RE, Day MP and Chernew ME (2012) The Alternative Quality Contract in Massachusetts, based on global budgets, lowered medical spending and improved quality, Health Affairs, 31(8): 1885-1894.

Sood N (2011) Medicare's bundled payment pilot for acute and postacute care: analysis and recommendations on where to begin, Health Affairs, 30(9): 1708-1717.

Spence AM and Zeckhauser RJ (1971) Insurance, information and individual action, American Economic Review, 61(2): 380-387.

Silberberg E (1990) The Structure of Economics: A Mathematical Analysis, San Francisco: McGraw-Hill.

Steel N, Maisey S, Clark A, Fleetcroft R and Howe A (2007) Quality of clinical primary care and targeted incentive payments: an observational study, British Journal of General Practice, 57(539): 449-454.

Town R, Wholey DR, Kralewski J and Dowd B (2004) Assessing the influence of incentives on physicians and medical groups, Medical Care Research and Review, 61(3): 80S-118S.

Tsiachristas A (2015) 'Payment and Economic Evaluation of Integrated Care', Doctoral Dissertation, Erasmus University Rotterdam.

Tsiachristas A, Dikkers C, Boland M and Rutten-van Molken MP (2013) Exploring payment schemes used to promote integrated chronic care in Europe, Health Policy, 113(3): 296-304.

Van Barneveld EM, Lamers LM, van Vliet RCJA and van de Ven WPMM (1998) Mandatory pooling as a supplement to risk-adjusted capitation payments in a competitive health insurance market, Social Science \& Medicine, 47(2): $223-232$.

Van de Ven WPMM (2014) 'Risk equalization and risk adjustment, the European perspective', In: A. J., Culyer (ed.) Encyclopedia of Health Economics, San Diego: Elsevier, 281-288.

Van de Ven WPMM and Ellis RP (2000) 'Risk adjustment in competitive health plan markets', In: A. J., Culyer and J. P., Newhouse (eds) Handbook of Health Economics, Amsterdam: Elsevier Science, 1003-1092.

Van Exel NJ, Koopmanschap MA, Scholte op Reimer W, Niessen LW and Huijsman R (2005) Cost-effectiveness of integrated stroke services, QJM, 98(6): 415-425.

Van Vliet RCJA (1992) Predictability of individual health care expenditures, The Journal of Risk and Insurance, 59(3): 443-461. 
Vermaas A (2006) 'Agency, Managed Care and Financial-Risk Sharing in General Medical Practice', Doctoral Dissertation, Erasmus University Rotterdam.

Vlaanderen FP, Tanke MA, Bloem BR, Faber MJ, Eijkenaar F, Schut FT and Jeurissen PPT (2018) Design and effects of outcome-based payment models in healthcare: a systematic review, European Journal of Health Economics, doi: 10.1007/ s10198-018-0989-8 [Epub ahead of print].

Von Eije JH (1989) 'Reinsurance Management: A Financial Exposition', Doctoral Dissertation, Erasmus University Rotterdam.

Welch WP (1999) Bundled Medicare payment for acute and postacute care, Health Affairs, 17(6): 69-81.

Wilensky GR (2014) Medicare physician payment reform in 2014 is looking unlikely, The Milbank Quarterly, 92(2): $182-185$.

Cite this article: Cattel, D. et al. 2020. Value-based provider payment: towards a theoretically preferred design. Health Economics, Policy and Law 15: 94-112, doi:10.1017/S1744133118000397 